\title{
The Implementation of the Mixed Techniques in Teaching English in Public Elementary Schools
}

\author{
Salwa Al Darwish ${ }^{1}$ \\ ${ }^{1}$ English Department, College of Basic Education, Public Authority for Applied Education \& Training, Kuwait \\ Correspondence: Salwa Al Darwish, English Department, Sabah Al Salem, Block 7, St. 2, Avenue 18, House 35, \\ Kuwait. Tel: 99-01-3946. E-mail: salwaaldarwish@hotmail.com
}

Received: October 9, 2016

Accepted: November 11, 2016

Online Published: March 29, 2017

doi:10.5539/ies.v10n4p31

URL: https://doi.org/10.5539/ies.v10n4p31

\begin{abstract}
Kuwait, an Arabic-speaking country in which English serves important functions, has adopted so many methods in teaching EFL in public schools which in 1993 started with the Grammar-Translation and continued until 2005 the eclectic method was applied. In 2005 the emphasis on communicative techniques and almost entirely through listening and speaking in the first grade was used. This qualitative investigation of the opinions and teaching practices of twelve first grade teachers found that certain communicative techniques were seen by many of the teachers to contribute to slow academic progress and motivational problems: not translating vocabulary, not overtly correcting errors, not teaching reading and writing, and not giving formal tests. In spite of the important functions of the English language in Kuwait, it appeared that most of these first graders were not hearing English outside the classroom, which appears to be important for the success of the communicative method. Most teachers and some parents were concerned that the children were not being prepared for formal examinations in their future. The conversational frame of the drills and recitations probably contributed importantly to students' understanding of English as a functional language. However, the communicative aim of encouraging students to absorb English through hearing it conversationally was undercut when the non-native-speaking teachers modeled English mistakes.
\end{abstract}

Keywords: curriculum, approaches, mixed method, public schools, elementary stage

\section{Introduction}

This study takes place in the context of worldwide experimentation over how best to synthesize traditional teaching methods, such as the audio-lingual and grammar- translation approaches, with communicative language teaching (CLT), which for several decades has been widely regarded as the best way to teach English as a second (ESL) or foreign (EFL) language. This new debate is engaging educators in many regions of the world, including, as this paper illustrates, the Arab world. In a situation that has some of the hallmarks of a paradigm shift, the reactions of teachers to their curricula may be valuable in explaining the reasons for methodological change. In fact, input from teachers may often be elicited by the designers of curricula, as it is in Kuwait. In this study, the researcher has attempted to investigate and understand the influences that are being brought to bear on the evolving Kuwaiti English curriculum.

\section{Background of the Current Methodology Debate}

Brown speaks of the "changing winds and shifting sands" of language teaching, which seem to have produced a major new method about every quarter of a century, each presenting a break from its predecessor, but usually keeping some aspects of previous methods (Hussein 1989, Richards and Rodgers 1986, Brown 1980). These shifts have taught us a great deal about the situations in which different methods are most useful. For that reason, methods that have fallen out of general favor tend to continue to be used in special circumstances: grammar-translation, for instance, when learners do not need to speak the language, and the direct method when learners need to achieve fluent conversation rapidly in environments where English is not normally heard (Al-Darwish, 2006; Hussein, 1989; Howatt, 1984; Hammerly, 1982).

CLT has been the preferred way to teach ESL and EFL since the 1970s, and English teachers generally are familiar with its emphasis on situational, student-centered communication, nonjudgmental teaching, and inductive learning of vocabulary and grammar from conversation (Al Darwish, 2006). The assumption 
underlying the method is that language is learned most naturally and effectively as part of genuine communication with other people (S. Kitao \& K. Kitao 1999; Met \& Galloway, 1992; Rosenfield \& Berko, 1990; Savignon, 1983). However, CLT has come under tire as English teaching has spread in areas where many people have no contact with native English speakers. With increasing globalization, English has come to be used as a lingua-franca in many situations: science and technology research, international diplomacy and business, and communication at many levels between speakers of different languages.

Proponents of the English as an international language (EIL) approach in fact discuss which phonetic contrasts and grammatical rules might be dispensed with in simplifying English into a global lingua franca (Rajadurai, 2005; Hung, 2004; McKay, 2002, 2003; Kirkpatrick, 2002; Jenkins, 2000; MacArthur, 1998; Pennycook, 1994; Kachru, 1992a, b). As a consequence of the widening use of English, many countries have imported teachers and teaching methods from the up and U.S.; that is, CLT has been introduced into hundreds of classrooms taught by non-native English speakers in areas where English is not commonly spoken. For the average student in these classes, native-like fluency in conversation, the goal of CLT, is much less important than accurate vocabulary, grammar, and spelling that will enable them to read their science textbooks, and pass their English subject exams. Learning vocabulary and grammar by induction or unconscious absorption from conversation is likely to proceed slowly in situations where the lessons do not echo and reinforce the English the children are learning from their environment, as happens in ESL classrooms in English-speaking countries. Furthermore, it is difficult for teachers with weak English proficiency to model natural conversation accurately. Consequently, it is not unusual for CLT programs to incorporate memorization and drill, especially in the earliest grades, in order to teach the basic building blocks of the language rapidly. In these changing programs, teachers, administrators, test-givers, and educational policymakers may hold different views on the best way to teach English with resulting confusion of aims (Nkosana, 2008; Kam \& Wong, 2004; Kam, 2004; Bax, 2003; Holliday, 1997).

In addition to these very important practical difficulties, the student-centered approach of CLT is offensive to cultural traditions that view respect for the authority of the teacher as central to the learning process. Fluency at the expense of accuracy, the heart of the communicative method, also has a negative value in cultures in which people assume that accurate, appropriate, and dignified language is more important than fluency in interacting with native English speakers (Li, 2005; Kam \& Wong, 2004; Hu, 2002; Rao, 2002; Ellis, 1996). A number of studies have found that tertiary level ESL and EFL students strongly prefer to have their teachers and native-English-speaking friends correct their oral errors (Katayama, 2007; Hawkey, 2006; Peacock, 2001; McCargar, 1993; Oladejo, 1993). These cultural observations have frequently come from Far Eastern cultures. However, Liu finds that Chinese university students may be more accepting of some student-centered techniques than has been reported in the past (2006).

Even the bedrock assumption of the communicative method-that language is learned more effectively if it is absorbed unconsciously from natural conversation-is now subject to renewed questioning and research. Macaro and Masterson surveying the literature on methods of teaching EFL grammar through 2004, show that findings conflict and that there is no conclusive advantage for either implicit or explicit grammar teaching (2006). Students learning grammar by implicit induction may never master the more difficult grammatical rules on the other hand, it is not clear that explicitly taught grammar is ever fully internalized. Macaro and Masterson also describe evidence that CLT (implicit) learning of grammar by university students may be more effective than explicit learning if it takes place in a country where the language is spoken by everyone, and if the |'natural" conversation students hear in the classroom is structured to call attention to target grammatical patterns (Klapper \& Rees, 2003; Doughty \& Williams, 1998). Strikingly, Macaro and Masterson suggest that explicitly learned grammar facilitate implicit learning of the same grammatical pat-terns, and thus a combination of the two may be more effective than either alone (2006).

\section{Research Questions}

At a time that shows some of the hallmarks of a pattern shift, the reactions of teachers to their curricula are even more significant than they might be at another time; input from teachers may often, in fact, be elicited by the designers of curricula, as it is in Kuwait.

This study investigates teachers' reactions to their mandated teaching techniques in an attempt to understand the influences that are being brought to bear on the changing Kuwaiti curriculum. Three questions are posed:

1) What was the nature of the first and second grade curriculum in Kuwait?

2) How did twelve first and second grade teachers view it and implement it in the classroom?

3) What factors appeared to be influencing their attitudes and choices? 
The focus on first grade was guided by the impression that some parents were more dissatisfied with the curriculum in the early grades, which suggested that problems and disagreements might be concentrated at that level.

\section{Setting of the Study}

El-Dib classifies Kuwait as a hybrid ESL-EFL country, and indeed, English may be more widely known there than in some other Arab countries (2008). It has been a core secondary school subject since 1911 (Al-Aryan 1988), and today, all oil companies, hospitals, banks, and technical establishments use English in communicating with the outside world, and English is the medium of instruction in the science, engineering and medicine colleges at Kuwait University and the Public Authority for Applied Education \& Training. In 1988, Hajjaj found that secondary teachers sometimes used English outside the classroom in school activities, and in 2006, Farghal and Haggan observed that it was natural for some English majors at Kuwait University to mix Arabic and English comments in conversation (1988). Private English-only schools are available in Kuwait, and many Kuwaitis take family vacations to English-speaking countries or send their children to school there. English language movies and books are available and some stores carry English signs. Furthermore, English is the lingua-franca used to communicate with the large foreign workforce in Kuwait. But on the other hand, Arabic remains the language of the family and everyday life and most children rarely hear English spoken. Moreover, there are two ethnic populations in Kuwait, speaking different Arabic dialects. While the Hadhar (originally from the trading town of Kuwait City) are thought to welcome outside cultures, the Bedouin (originally from the desert and remote towns) are thought to be suspicious of foreign influences, including English (Al Darwish, 2006). This difference is not deeply divisive, as the population is overwhelmingly Arab and has a strong sense of national identity, but it affects classroom attitudes.

English teaching has changed over the years, in part in response to changes in the attitudes of the profession, but also in response to perceived weaknesses in successive approaches as they were applied in Kuwait. Grammar-translation was adopted in the 1950s, the audio-lingual approach in the 1960s, and CLT in the mid-1970s, gradually modified by increased emphasis on explicit, analytical teaching, drilling, and testing in order to teach better accuracy (Al-Bazzaz, 1994; Mabrouk \& Khalil, 1989). In 1993, English was introduced into the elementary schools, starting in first grade. In 2002, the Kuwait Ministry of Education announced that the curriculum would blend communicative, audio-lingual, and grammar-translation approaches, but the approach was kept more communicative in the earliest grades. (Communicative and audio-lingual emphasis returns in university English classes.) Because of a perceived lack of adequate literacy teaching, the Ministry of Education announced in 2005 that the elementary curriculum was to be modified to give equal weight to the four skills of speaking, listening, reading, and writing. Literacy was to be introduced slowly in the earliest grades, however. Thus, by a process of experiment and adjustment, Kuwait has arrived at a blended English curriculum.

\section{Method}

This is a qualitative, multi-method study (Richards, 2003), including non-participant observation in the classroom, individual interviews with teachers and parents and analysis of artifacts such as textbooks, workbooks, teachers' guides, lesson plans, and visual and aural aids.

\subsection{Data Collection}

The data collection and some of the analysis were carried out over the fall of 2014 . The researcher observed each teacher in the classroom for one forty five minute class period a day, two days a week, during two periods of two weeks each. The first two-week period occurred in September, at the beginning of the school year. The second period occurred about the middle of the semester, in November and December, when teachers had had an opportunity to cover part of the curriculum. Both reflective and descriptive notes were made of the classroom teachings. After the first two-week observation period, each teacher provided the researcher with an individual interview in the school, lasting about an hour. Participants were reminded that the information they were sharing was confidential. The researcher also had brief formal interviews with English department heads and school principals, and informal interviews with some parents. These interviews were guided by questions arising from analysis of the data. The interviews were all tape-recorded and transcribed by the researcher, and the transcripts were checked for accuracy by the interviewees. At the end of the research period, the researcher gave each teacher a chance to read a preliminary draft of her case and comment on whether the researcher's description of her views and teaching approach accurately mirrored her understanding of it. She also examined artifacts such as the teachers' manuals and visual aids that were used by each teacher during the explanation of her lesson. 


\subsection{Influence of the Observer on Classroom Teaching}

There was evidence from several sources that teachers were uncomfortable at being observed specially the ones who used to be students in the researcher's classes before graduating from college. Moreover, in some cases they may have followed the official lesson plans more rigidly, taking fewer risks and innovating less, when they were being observed. However, the main effect of observation seems to have been that the teachers took care to be better prepared than they sometimes were, even to the extent of repeating classes they had taught recently.

\subsection{Participants}

The research sites for this study were twelve elementary English classrooms in the only six school districts in Kuwait. A single school within each district was selected for this study by the Ministry of Education of Kuwait. Two English teachers in each school were then chosen by the school authorities. The researcher had asked to observe and interview only first grade teachers. It should be explained that in Kuwaiti elementary schools, each subject is taught by a separate teacher specialized in that subject. The children remain in their home rooms, except for recess and assemblies, and the teachers come to them. This provides students with the educational advantage of specialized teachers, but subjects are not likely to be brought up again in connection with other subjects throughout the day.

The twelve teachers presented somewhat diverse backgrounds. Eight were beginning teachers, not a surprising proportion at present, when Kuwaiti English teachers are being educated to replace foreign teachers. The other four had each taught for several years. Six of the twelve teachers had been trained in the English program at the College of Basic Education (CBE; a Kuwait's elementary-level education training college). Another two teachers were trained in the English Education Program at Kuwait University, which is designed to prepare teachers for middle and high school. The other four had found their way to English teaching after completing Kuwait University majors in linguistics and English literature, respectively, followed by summer workshops on teaching English. Eight of the twelve teachers came from a Bedouin background, had not traveled outside the country, and were usually doubtful about expressing opinions on how to teach English.

\section{Results}

In the analysis, six major themes emerged as foci of concern or disagreement over method: how much to translate English into Arabic, whether to correct errors overtly, whether there should be formal and explicit testing, whether reading and writing should be taught in first grade, students' motivational problems, and teachers' English proficiency, According to the teachers, the Kuwait Ministry of Education was keenly interested in the success of various aspects of the curriculum in the classroom, and had invited schools to forward teachers' written comments on the textbook and curriculum.

\subsection{The First Grade Curriculum}

The Kuwait Teacher's Manual for first grade English (Kuwait Ministry of Education, 2005) presented the curriculum in detail, including daily lesson plans for almost the entire school year, leaving some extra days for review. Five units were covered in the first semester followed by another five units, each with a separate set of vocabulary to be learned and practiced. Colors, numbers, body parts, and home and food vocabulary were observed in the study. The first grade manual for 2008-2009 (Ministry of Education 2008), which is very much like that for 2005-2006 (Ministry of Education, 2005), contains a useful explanation of the goals of the eclectic method that the Kuwait schools use. The manual says:

To ensure that pupils will learn to use English both fluently and accurately, the Fun with English syllabus has been designed according to an integrated approach using both traditional structural and communicative approaches. Many integrated approaches have been discussed in various texts and articles. Their purpose is to preserve the accuracy of the analytical methods of a traditional approach while still making use of authentic communicative activities for the pupils.

It is important to understand that the main thrust of an integrated approach is still communicative, which means that it is of prime importance to provide pupils with authentic opportunities for communication and continuous practice in order to gain fluency. Traditional structural methods are integrated primarily in the communication already taking place in the classroom, for correction, analysis, or in response to pupils' questions. Fluency is important, but learners tend to exploit the linguistic forms they have already mastered along with new and more complicated structures. This is why an integrated approach is necessary.

There are two main ways of integrating accuracy and fluency work. One involves "ppp" (present, practice, produce). This is basically a structural approach that incorporates a final free production stage where learners have the chance to use the structure they have been practicing in a communicative activity, where 
they are primarily focused on meaning. The second method of integration involves the use of communicative activities only, within which there is no attempt to present and practice specific grammatical structures. In this approach, the teacher encourages pupils to use grammar accurately by providing feedback as they produce certain structures. The method used in Fun with English utilizes both of these integrated approaches ., . [and aims to] present and practice new linguistic itemed but also aims to provide communicative activities to reinforce them, and additional communicative activities outside the PPP sequence are also offered. Teachers using this model will teach pupils the grammatical structures that they need to know so that learners are able to accomplish communication tasks both fluently and accurately.

At the primary level, the traditional structural approach is of limited value, and should be reserved for the use of simple models and repetition. Meaning should be emphasized more than the various forms that the pupils are required to learn. However, it is important for pupils to hear the language in its correct form and to be able to imitate the models accurately. In addition, they should always be given praise and encouragement.

It is naturally difficult to achieve genuine, active communication among children who do not yet know a language, as most of these first graders did not. Necessarily, therefore, the recitation and discussion questions that the researcher observed were narrow and drill-oriented, designed to elicit repetition rather than open-ended conversation. On the other hand, class drills and recitations almost always took the form of question-and-answer or similar conversational rituals, so that drills had a flavor of real conversation, and could be transferred easily to real conversational situations. The avoidance of translation, error correction, and other explicit teaching techniques may have favored the internalization of the functions of words rather than their conscious memorization.

Classes always stated with a ritual of greeting: good morning, class! Good morning, teacher! How are you, class? Fine, thank you, and you? I'm fine, thank you. Teachers then presented pictures of vocabulary items on flash cards or wall charts, or, more rarely, made gestures, such as for climbing or kicking, and asked "that is this?" The class called out the answers, such as "it's a hand." After students practiced a new item a few times, teachers often accelerated the pace, to have time to go on to the next item, without checking whether most of the children had learned the new material. The same vocabulary would be presented again over several weeks, with variations in the type of drill. Grammatical vocabulary was presented in ways that emphasized distinctions, such as "this ballthat ball," and was expected to be absorbed, with or without precise understanding, from context.

Classes typically ended with games, such as having several children run together to a wall chart and point to the correct pictures, as the teacher said the words, or with listening to recorded English songs and singing along with them, or with workbook exercises. A typical exercise involved making an $\mathrm{X}$ beside a picture if the teacher called out the wrong name for it. The teachers' manuals encouraged teachers to have children review vocabulary and play games in small groups or pairs, which might have involved more genuinely communicative exchanges, but this was not observed, This was probably in part because the classrooms were too small to successfully break classes of over 20 children into separate groups, owing to the rapid expansion of education in Kuwait and the recent transfer of fifth grade students to elementary schools. Another reason teacher did not use pair or small-group work was their concern about losing control of the children's activities. The children often clearly enjoyed the songs, which enabled them to have fun and feel more involved with English. As the Teacher's Manual notes, songs are important because they model native stress, intonation, and pronunciation.

An important element in many language curricula was absent in this first grade curriculum: information about the cultures of the countries in which English is spoken. The English language songs the children heard and learned concerned topics in Kuwaiti culture rather than in English-speaking cultures. Teachers might have remedied the deficit with pictures or other material from the internet, magazines, newspapers, children's books, or English nursery rhymes or stories, but perhaps these young children were more interested in songs about topics they knew and loved. The absence of this material from the early curriculum may also have reflected deference to the doubts of a large minority of parents about teaching foreign culture in Kuwaiti schools. The researcher confirmed the presence of distrust of learning English through an informal survey of parents in one of the school districts with a fairly high proportion of Bedouin families. In the long run, however, a language cannot be adequately understood and used without knowledge of its culture, as Majdzadeh (2002) notes.

\subsection{Arabic Translation of English Vocabulary}

Classes were carried out largely in English, and the teachers reported they believed they would be marked down by class inspectors if they did not teach meaning from context only. A beginning teacher, related how she managed to explain "sandwiched" contextually. 
I said "Do you eat a sandwiching and showed them a flash card of a hamburger. They all raised their hands and said in one voice "McDonald's" So I had to use another picture of cheese and honey, and describe to them a sandwich made of these two ingredients. In other cases, if they still don't follow, then I have to translate into Arabic. However, there are always a couple of advanced students who follow what I'm doing and can serve as models.

Three of the twelve teachers expressed frustration with the ban on Arabic translation of English vocabulary, and one beginning teacher was not sure of her opinion, These three teachers felt that an English-only curriculum was unrealistic with beginning students and that it deprived the children of useful knowledge, Two of the teachers, preferred more explicit teaching and followed through themselves in the classroom. Experienced teacher commented that the pure communicative method was inappropriate because "first-graders are not ready to talk in English about activities they are participating in." Yet the same experienced teacher also developed some creative communicative techniques. Two teachers did not hesitate to use Arabic in order to bring all the children along either in their understanding or in doing an exercise or game correctly.

This seemed to have the effect of keeping up momentum. The other ten teachers were more likely to continue trying to indicate meanings from context, and sometimes even kept the children repeating sentences they did not understand, which of course did not carry out communicative goals. Classes often ended with some children still not seeming to understand the meanings of the words they had been repeating.

Another two of the experienced teachers, who had spent four years in the U.S. and U.K. as a child, had exactly the opposite reaction to grammar-translation. They remembered with distaste the heavy schoolwork and frequent tests they endured learning formal English grammar and translation in middle and high school in Kuwait. They thought students today were fortunate to begin English in first grade rather than fifth, and to speak and listen and play games for several years. They believed this gave them a better sense of English as a real language than these two experienced teachers had received in school. "Look at the title of the textbook!" one of the two experienced teachers said. "Fun with English tells you everything about this book!" Yet the same teacher was also one of readiest teachers to translate into Arabic, and she also experimented with explicit teaching of grammar. The other experienced teacher was also in favor of the communicative method, which she said brought reality into the classroom and helped students visualize and understand the vocabulary items "without requiring too much effort from the teacher." When asked about her goals in teaching, she said her only goal was to repeat all language items a few times so the children would remember them.

The sentences and phrases in which the vocabulary was embedded were not translated, and these first graders seemed not to be picking up the grammatical distinctions that were presented, such as "this is- these are" and Imy." One beginning teacher, made an innovative attempt to explain "my" from context. She brought twin sisters to the front of the class and had each one say, "this is my sister." However, the class failed to understand, and the teacher let it go rather than translate- and in fact used "my" several times in confusing ways, such as saying "[textbook character's name] is my sister" and "[student's name] is my sister," which could only have deepened the mystery about the word's meaning, One teacher who was an English literature major with a deep love for English language and culture, actually believed that grammar-translation was the perfect method to teach beginning English. After students had mastered the basics of the language, she believed, they would be ready to acquire fluency and an understanding of cultural nuances, using the communicative method. Nevertheless, this teacher was among the teachers who seldom gave Arabic translations for words.

All twelve teachers expressed discomfort at trying to teach grammar without translation.

One teacher said she had not learned how to teach English because her major was linguistics, and she was finding her way as she taught. "The way I understand grammar in my head might be different from the way the students understand... I wonder if I should teach grammar thoroughly, the way I learned it." Another teacher who lived in English-speaking countries for four years before studying English in Kuwait, had avoided the communicative approach for a while, but had recently returned to explicit teaching of grammar. She said, "I think students do learn from indirect approaches, especially if they are motivated. . I think grammar without use is pointless."

These teachers had themselves begun learning English in middle school, in a curriculum with strong elements of grammar and translation, and thus they expected the children to acquire more rapid explicit understanding than they were doing. It is possible that the practice in the curriculum of presenting grammatical distinctions without explaining them sometimes motivated students to try harder to guess their meanings. Unfortunately, most of the children did not seem to have heard much, or any, English outside the classroom, so the process of learning the meanings of "my" or "this- these," if they were not explicitly taught, was necessarily slow. The perception that 
the children were not learning as much English as they might have been was general among the teachers. They also believed that a number of the parents (most of whom had also learned by the grammar-translation method) felt the children were not making appropriate progress. Still another reason for their concern was voiced by a beginning teacher: "We often hear from native English-speaking teachers that our students are terribly lacking in basic grammar and vocabulary." The researcher was also surprised at how little the children seemed to know, after half a semester of reciting and drilling.

In spite of the teachers' belief that translation was forbidden, the Teacher's Manual actually advised them to translate vocabulary if the children did not understand. The 2005-2006 first grade Teacher's Manual said that English should be the main language of the classroom, but it also said that "it is obviously imperative that pupils understand new vocabulary being presented", and, therefore, that Arabic translation should be given whenever the meaning was not clear from context. The manual also warned against using too much Arabic, however, because the goal of the curriculum was to immerse the children in English so that they would understand English through use. Nevertheless, a majority of teachers appeared to be avoiding translation in contravention of the instructions in the Teacher's Manual and their own instincts.

The teachers believed that they were marked down during class inspections if they used Arabic. The principals who sometimes attended the classes with the researcher were all experienced teachers who occasionally gave workshops on teaching, but their main responsibility was to evaluate the teachers for the Ministry of Education. The evaluations affected teachers' salaries and of course had great influence on how the teachers taught, since they had to be prepared to pass an inspection on any lesson. The principals all stressed the importance of the communicative ideal of learning through natural conversation, and indicated they were evaluating the teachers in part on the extent to which they emphasized implicit learning, following the lesson plans in the teachers' manuals and the recommendation of the head of the English Department.

Several of the comments by department heads implied that the teachers did not understand the communicative method. The researcher did not have an opportunity to observe inspections and study the reports, in order to confirm the teachers' report that department heads held teachers to a stricter communicative practice than the Teacher's Manual required. The contrast between the teachers' beliefs about what was required of them and the instructions in the manual seems to point to disagreement or confusion at some level about the degree of translation allowed in the official curriculum.

\subsection{Error Correction}

The first grade versions of the Kuwait Teacher's Manual instructed teachers not to correct children's mistakes, so as not to discourage or humiliate them, in accord with the communicative philosophy that children should become fluent and comfortable in English before experiencing pressure for accuracy. Instead of correcting, teachers were told to model the correct form after a short time had passed. An example of how this was often done comes from a class taught by one teacher:

Student 1, obeying her teacher's instructions: What's this? (pointing to her teacher's ear)

Student 2: This this an ear.

Teacher: This this an ear. (repeating the student's wrong reply).

Student 3: This is an ear.

Teacher: It's an ear. (Class repeated the sentence three times.) Excellent.

In general, teachers seemed to accept and follow this policy, although it seemed to the researcher that the mistakes that were not quickly corrected were sometimes repeated and possibly learned. In the above example, "This is an ear" was probably believed by the students to be an error. "This is . . " was not added to their vocabulary as an alternative to "It's ..." A beginning teacher who had an especially warm, reassuring relationship with her first grade students, didn't hesitate to say "No" to a wrong answer.

An experienced teacher, who also praised often, would make a doubtful face to signal that an answer was not correct, and then call on another student. On the other hand, another teacher once asked the class if a student's answer was correct, to which they all shouted, "No!" but such insensitivity was a typical. The department heads were apparently quite strict about not correcting errors. One department head explained her philosophy about this:"'it's very embarrassing to make mistakes, especially when there are students of different abilities. I was very self-conscious. . So I think once you make the students comfortable and reassure them that it is all right to make a lot of simple mistakes, then the real learning begins." 


\subsection{Formal Testing}

Serious testing was not undertaken in the first grade, in order to avoid making the children anxious about accuracy. The teachers believed that this may have influenced parents not to take the English program seriously, and that the children, in consequence, did not work as hard as in other subjects. One teacher, for instance, said, "Now that the Ministry of Education has announced that first grade will have no exams, the parents are not cooperating with the teachers, because they see English as a supplementary subject. Several teachers expressed worry that the children would not be ready for formal testing when it started in third grade, and that the teachers would be blamed if the children did not do well.

\subsection{Delay in Beginning Reading and Writing Instruction}

The English alphabet, reading, and writing were not included in the lesson plans at this early stage, although the teachers' manuals required first grade students to have copied or traced either the English numbers or the English lower case alphabet by the end of the first semester. The purely speaking and listening curriculum observed in these classrooms was apparently intended to carry out the communicative goal, mentioned in the Kuwait First Grade Teacher's Manual (2005-2006) of presenting English from the beginning as an authentic communicative activity that conveys meaning. Ten of the twelve teachers believed that the four language skills of reading, writing, speaking, and listening should be introduced together. One teacher saw a relationship between teaching all four skills and the children's interests and needs. "If we start with listening, students would like to see how the word is written and then how the letters are pronounced, although to write full sentences at this stage is impossible." Another teacher who had been an English literature major at Kuwait University, thought that music, reading, and writing should all be included in a communicative experience. "To me" she said, "communication is any way to express one's feelings, thoughts, and experiences." One teacher agreed that reading and writing along with speaking and listening provided a more balanced learning goal. She said she had been teaching the textbook for three years, and believed it should be re-evaluated in this direction for the sake of the children. Another teacher, who thought children should learn to enjoy English as a real language before studying it seriously, did not think reading and writing should be taught along with speaking and listening. Also, another teacher preferred to delay reading and writing, feeling that the children were having enough difficulty learning a foreign language in first grade.

At least four of the twelve teachers, were introducing reading and writing skills ahead of the curriculum. One beginning teacher, was teaching her first grade girls to sound out, read, and write English words in advance of the official curriculum, with apparent success. One of these four teachers, however, observed confusion among some of her first grade girls when she taught them to write their names. Some wrote their names in Arabic letters, but from left to right as in English, rather than from right to left. She felt that the children would learn faster without having to face this confusion at the beginning. In part because she believed all four skills should be taught together, she favored putting off English completely until middle school. She also argued that it was worthless to teach English so early, when the children were not using it except during a single class in school, because the learning went extremely slowly. She believed young students should learn their own language first, with its deep religious and cultural importance, before learning a language that involved some identification with a foreign country. No other teachers expressed an interest in delaying English completely until middle school. It seems unlikely that this would be implemented, because it is the same schedule system that was in place in Kuwait before 1993, and was changed because the students were felt not be acquiring enough English by the end of high school.

Furthermore, during the teachers' interview, the teachers reported that elementary school norms and values supported a hidden goal of teaching reading and writing ahead of the curriculum, in order to prepare children for future examinations. They felt caught in a dilemma between the curriculum's requirement to emphasize listening and speaking in the beginning grades, and the knowledge that these children would be expected to begin taking exams in reading and writing when they reached third grade. The teachers were concerned that the children would be taken by surprise, not prepared to remember what they had covered in class, and not far enough advanced in reading, writing, and grammar. Since the teachers would be held responsible if the children did not do well in third grade, they had an interest in trying to introduce more formal work early on, Also, teachers and English department heads in each school felt a responsibility to the more motivated students to prepare them, throughout elementary and secondary school, to pass the university entrance examinations.

In spite of their strong endorsement of communicative teaching, none of the teachers were pleased with the pure listening and speaking curriculum in the first grade. They echoed their comments and the comments of the parents in saying it was desirable to strike a balance between the four language skills of listening, speaking, 
reading, and writing, and that a pure listening and speaking curriculum was inadequate. All teachers were not satisfied with the current textbook because it contained limited material and did not contain goals for reading and writing skills. Thus, a majority of the teachers, parents, and probably the official test writers seemed to agree that reading and writing should be taught along with listening and speaking from the beginning. Possibly in response to this widespread view, the Ministry of Education had recently announced that reading and writing would be integrated with speaking and listening in the curriculum in the future.

\subsection{The Children's Motivation to Learn English}

All twelve teachers regarded student motivation as a critical problem. One reason may have been disapproval of English by conservative parents. One teacher remarked, "there is a big gap, a big wall. So many Kuwaiti people think (Why do my children have to take English? I can't speak English's." Another teacher said: "There is a wide gap..... I tried to make everyone understand me. Then the good students, who always prepared for class, got bored and went to sleep.... I have come to feel that I should teach English to those who really want to learn ....... I sometimes think it would be better for the students who like English ....... to study in a different classes." The researcher's interviews with parents in one of the school districts of Kuwait showed that they were a majority Bedouin population, and tended to have little interest in English language teaching at any level of education. The parents felt this even though they were aware that a lack of English would put their children at a disadvantage. Research shows that a majority of Bedouin students who graduate from Kuwait University have degrees that require little or no foreign language knowledge, such as Law, Religious Studies, or Human Studies. Thus it seems likely that two of the twelve teachers from that school district were facing a good deal of silent cultural opposition in their English classes.

However, this is not the whole explanation for the children's poor motivation, because the other three of the six districts in this study had majority Hadhar populations. In interviews, these parents usually expressed the belief that the English language added tremendous value to their children's educations, since most university majors require a strong command of English. Some were thinking of sending their children to private schools later on, or were planning to send them abroad for higher education. Research shows that Hadhar university graduates tend to major in fields that require strong English, such as medicine, science or engineering, These children were therefore not learning at home to disapprove of English, and there must have been other reasons for the motivational problems the teachers observed. It seems plausible that, as the teachers generally thought, the lack of translated vocabulary knowledge, the absence of exams, and the lack of reading and writing were causing some parents to see the English classes as lacking in substance and importance, as the teachers themselves tended to believe. The teachers' failure to make sure the children actually understood the meanings of English words could only have increased the impression that the children were making no progress. A third factor may have been that the students were too young to understand the value of learning words that no one around them used, and they might sometimes have become bored and dispirited at parroting words without learning their meanings.

\subsection{Teachers' Varied English Proficiency}

All the teachers expressed insecurity about their English proficiency in conversation, and, in fact, all twelve occasionally made errors in English grammar, pronunciation, and intonation in the classes that were observed, in spite of the guidance offered by the official lesson plans. Remarks that were recorded included:

"This is a honey" for("this is honey"),

"What do you can say?" for ("What do you say?"),

"How are today?" for ("How are you today?"),

"I find it." for ("I have found it.") and

"Who tell me what this" for ("Who can tell me what is this?")

Four of the teachers made very few errors, but the other eight made several in each lesson, even though the teachers had the English sentences written out in the daily lesson plans they were provided with. In the interviews, only two of the teachers, the linguistics major, responded in English when the researcher initiated the discussion in English. These difficulties are probably not unusual where English education is expanding rapidly in non-English-speaking countries, but assuming that these schools tended to select better English speakers to be observed, the level of conversational accuracy seem somewhat problematic for a speaking and listening curriculum. 


\section{Conclusions}

By a process of experiment and adjustment, Kuwait, like many nations, has developed its own blend of communicative, audio-lingual, and grammar-translation techniques to teach English. Disagreement about how to integrate CLT and other teaching approaches is still present among Kuwaiti teachers, test-givers, and policymakers, as has been noted in other EFL programs. Perhaps the most interesting finding of this study is that in spite of the important functions of the English language in Kuwait, and the view of many parents that English is a necessary second language, most of these first graders did not seem to have picked up English from extra-classroom sources, and had difficulty and, often, disinterest in grasping meanings of vocabulary from context. The practices of some teachers of not translating vocabulary when students did not understand and of not overtly correcting errors exacerbated this problem and seemed to slow down the momentum of the classes; but, on the other hand, not all teachers had the skill to make overt corrections kindly slid tactfully. Most of the teachers and many parents would have liked more translation and more formal memorization in first grade, as well as testing to increase the motivation to learn. An additional difficulty with absorbing English by hearing English conversation was that teachers fairly often modeled English mistakes. In short the emphasis on communicative methodology in the first grade, as compared with later grades, may be counterproductive for most Kuwaiti children.

Memorization and direct translation of vocabulary (although within the framework of simple conversations) should perhaps be emphasized in the earliest grades, with more emphasis on fluency later.

The ritual conversational exchanges_ "What is this?" "It's a ___."_ probably helped the children to understand English as a communicative language and provided them with constant opportunities to participate, although much real communication was not possible without more vocabulary. The failure of teachers to take advantage of suggestions in the curriculum to use small-group and pair work to promote communication may have reflected discomfort with student-centered learning. However, there is also reason to doubt that most children would have used those opportunities to practice their English. The flexibility of the system in promoting adaptation to Kuwait's circumstances was shown by the policy of the Ministry of Education of soliciting teachers' reactions to the curriculum. Shortly before this study, the ministry had responded to a widespread desire for more emphasis on reading and writing in the early grades by announcing that change. Whether most students will be able to master right-to-left Arabic script at the same time as left-to-right English script remains to be seen. This responsiveness, however, is especially important in a situation in which methodology is still taking form.

\section{References}

Al Aryan, J. (1988). A study of the implementation of the new social studies curriculum in the intermediate stage of the Kuwaiti educational system (Unpublished doctoral dissertation). University of Sussex, Sussex, UK.

Al Darwish, S. (2006). An Investigation of teachers' perceptions of the English language curriculum in Kuwaiti elementary schools (Unpublished doctoral dissertation). University of Denver, Colorado, USA.

Al-Bazzaz, A. (1994). The student low achievement in Business English at the College of Business Studies in Kuwait (Unpublished doctoral dissertation). University of Sussex, Sussex, UK.

Bax, S. (2003). The end of CLT: a context approach to language teaching. ELT Journal, 5(3), 278-287. https://doi.org/10.1093/elt/57.3.278

Brown, H. D. (1980). Principles of language learning and teaching. Englewood Cliffs, New Jersey: Prentice-Hall, Inc.

Creswell, J. (2003). Research design: Qualitative, quantitative, mixed method approaches (2nd ed.). Thousand Oaks, CA: Sage Publications, Inc.

Doughty, C., \& Williams, J. (1998). Focus inform in classroom second language acquisition. Cambridge: Cambridge University Press.

El-Dib, M. A. B. (2008). Language learning strategies in Kuwait: Links to gender, language level, and culture in a hybrid context. Foreign Language Annals, 37(1), 85-95. https://doi.org/10.1111/j.1944-9720.2004.tb02176.x

Ellis, G. (1996). How culturally appropriate is the communicative approach? ELT Journal, 50(3), 213-218. https://doi.org/10.1093/elt/50.3.213

Farghal, M., \& Haggan, M. (2006). Complement behavior in bilingual Kuwaiti college students. International $\begin{array}{lllll}\text { Journal of Bilingual Education and Bilingualism, 9(1), 94-118. } & \text {. }\end{array}$ https://doi.org/10.1080/13670050608668632 
Hajjaj, A. H. S. (1988). Formalizing informal EFL teaching and learning. Report Abstract. Literacy Investment for Tomorrow: St. Louis, MO.

Hammerly, H. (1982). Synthesis in second language teaching: An introduction to linguistics. Blaine, Wash.: Second Language Publication.

Hawkey, R. (2006). Teacher and learner perceptions of language learning activity. ELT Journal, 60(3), 242-252. https://doi.org/10.1093/elt/ccl004

Holliday, A. (1997). The politics of participation in international English education. System, 25(3), 409-423. https://doi.org/10.1016/S0346-251X(97)00032-8

Howatt, A. P. R. (1984). A history of English language teaching. Oxford: Oxford University Press.

Hu, G. W. (2002). Potential cultural resistance to pedagogical imports: The case of communicative language teaching in China. Language, Culture and Curriculum, 15(2), 93-105. https://doi.org/10.1080/07908310208666636

Hung, T. T. N. (2004). English as a language of wider communication in East Asia today: The issue of mutual intelligibility. In Kam and Wong eds. English Language Teaching in East Asia Today: Changing Policies and Practices (2nd ed.). Singapore: Marshall Cavendish International.

Hussein, Y. I. (1989). The relationship between attitudes of English teachers in Egypt toward methods of teaching English and selected demographic characteristics (Unpublished doctoral dissertation). George Washington University, Washington, D.C.

Jenkins, J. (2000). The phonology of English as an international language. Oxford: Oxford University Press.

Kachru, B. B. (1992b). World Englishes: Approaches, issues and resources. Language Teaching, 25, 1-14. https://doi.org/10.1017/S0261444800006583

Kachru, B. B. (1992a). The other tongue: English across cultures. Urbana: University of Illinois Press.

Kam, H. W. (2004). English language teaching in East Asia today: An overview. In H. W. Kam, \& R. L. Wong (Eds.), English language teaching in East Asia today: Changing policies and practices. Singapore: Marshall Cavendish International.

Kam, H. W., \& Wong, R. L. (2004). Aim, scope, and concepts. In H. W. Kam, \& R. L. Wong (Eds.), English language teaching in East Asia today: Changing policies and practices (2nd ed.). Singapore: Marshall Cavendish International.

Katayama, A. (2007). Japanese EFL students' preferences toward correction of classroom oral errors. Asian EFL Journal, 9(4), 19.

Kirkpatrick, A. (2002). Englishes in Asia: Communication, identification, power, and education. Australia: Language Australia.

Kitao, S. K., \& Kitao, K. (1999). Fundamentals of English language teaching. Tokyo: Eichosha Co. Ltd.

Klapper, J., \& Rees, J. (2003). Reviewing the case for explicit grammar instruction in the university foreign language learning context. Language Teaching Research, 7(3), 285-314. https://doi.org/10.1191/13621688031r128oa

Kuwait Ministry of Education. (2005). Kuwait First Grade English Teacher's Manual. Kuwait: Kuwait Government Press.

Kuwait Ministry of Education. (2008). Kuwait First Grade English Teacher's manual. Kuwait: Kuwait Government Press.

Kuwait Ministry of Planning: Statistics and Information Sector. (2002). Annual Statistical Abstract (39th ed.). Kuwait: Government Printing Office.

Li, X. (2005). An analysis of Chinese EFL learners' beliefs about the role of rote learning in vocabulary learning $\begin{array}{lllll}\text { strategies. Asian } \quad \text { EFL } & \text { Journal, } & \text { Retrieved from }\end{array}$ https://www.asian-efl-joournal.com/xiuping_11-05_thesis.pdf

Liu, J. (2007). The place of methods in teaching English around the world. In J. Liu (Ed.), English teaching in China: New approaches, perspectives, and standards. London and New York: Continuum International Publishing Group.

Mabrouk, F., \& Khalil, F. (1989). EFL common core; a step down the right path to second language mastery of 
ESP courses. ESP Symposium on the Teaching of English as a Banking Language, Kuwait.

Macaro, E., \& Masterman, L. (2006). Does intensive explicit grammar instruction make all the difference? Language Teaching Research, 10(3), 297.

MacArthur, T. (1998). The English languages. Cambridge: Cambridge University Press,

Majdzadeh, M. (2002). Disconnection between language and culture: A case study of Iranian English textbooks. Report. EDRS. ED 474691.

McCargar, D. (1993). Teacher and student role expectations: Cross-cultural differences and implications. Modern Language Journal, 77(2), 192-207. https://doi.org/10.1111/j.1540-4781.1993.tb01963.x

McKay, S. L. (2002). Teaching English as an international language: Rethinking goals and approaches. Oxford: Oxford University Press.

McKay, S. L. (2003). Toward an appropriate EIL pedagogy: Reexamining common ELT assumptions, International Journal of Applied linguistics, 13(1), 1-22. https://doi.org/10.1111/1473-4192.00035

Met, M., \& Galloway, V. (1992). Research in foreign language curriculum. In Jackson, P. H. W. (Ed.), Handbook of research in curriculum: A project of the American Educational Research Association. New York: Macmillan Publishing Company.

Nkosana, L. (2008). Attitudinal obstacles to curriculum and assessment reform. Language Teaching Research, 12(2), 287-312. https://doi.org/10.1177/1362168807086297

Oladejo, J. (1993). Problems and prospects of ESP in multilingual learning-contexts: An alternative approach. Paper presented at SEAMEO RELC Conference, Singapore.

Peacock, J. (2001). Match or mismatch? Learning styles and teaching styles in EFL. International Journal of Applied Linguistics, 11(1), 1-20. https://doi.org/10.1111/1473-4192.00001

Pennycook, A. (1994). The cultural politics of English as an international language. London: Longman.

Rajadurai, J. (2005). Revisiting the concentric circles: Conceptual and sociolinguistic considerations. Asian EFL Journal, 7(4)

Rao, Z. H. (2002). Chinese students' perceptions of communicative and non-communicative activities in EFL classroom. System, 30(1), 85-105. https://doi.org/10.1016/S0346-251X(01)00050-1

Richards, J. C. (2001). Curriculum development in language teaching. Cambridge: Cambridge University Press. https://doi.org/10.1017/CBO9780511667220

Richards, K. (2003). Qualitative inquiry in TESOL. Palgrave MacMillan. https://doi.org/10.1057/9780230505056

Rosenfield, L., \& Berko, R. (1990). Communicating with competency. Glenview, Illinois: Scott Foresman \& Company.

Sano, M., Takahashi, M., \& Yoneyama, A. (1984). Communicative language teaching and local needs. ELT Journal, 38(3), 170-177. https://doi.org/10.1093/elt/38.3.170

Savignon, S. J. (1 983). Communicative competence: Theory \&practice; Texts and contexts in second language learning. Reading, MA: Addison Wesley Publishing Company.

\section{Copyrights}

Copyright for this article is retained by the author(s), with first publication rights granted to the journal.

This is an open-access article distributed under the terms and conditions of the Creative Commons Attribution license (http://creativecommons.org/licenses/by/4.0/). 